\title{
Quality of life in sexagenarians after aortic biological vs mechanical valve replacement: a single-center study in China
}

\author{
Li-Wen Wang ${ }^{1,2+}$, Ning $\mathrm{Xu}^{1,2+}$, Shu-Ting Huang ${ }^{1,2}$, Liang-Wan Chen ${ }^{2}$, Hua Cao ${ }^{1 *}$ and Qiang Chen ${ }^{1,2^{*}}$ (D
}

\begin{abstract}
Objective: This article aimed to study the quality of life and anxiety of sexagenarian patients who underwent aortic biological vs mechanical valve replacement in a single center in China.

Methods: The clinical data of 78 patients aged 60 to 70 years who underwent aortic prosthetic valve replacement were retrospectively analyzed in our hospital from June 2017 to February 2018. Patients were divided into two groups depending on the type of prosthetic valve they received (biological valve group vs mechanical valve group). The SF-36 was completed by all patients at discharge and at one-year follow-up, and the cardiac anxiety questionnaire (CAQ) was also completed at one-year follow-up.

Results: There was no statistically significant difference between the two groups in general clinical data or SF-36 score at discharge. However, at one-year follow-up, the SF-36 scores were significantly higher in the biological valve group than in the mechanical valve group, and the CAQ scores in fear and anxiety, avoidance and attention in the mechanical valve group were significantly higher than those in the biological valve group.

Conclusions: Based on the postoperative quality of life and anxiety scores of sexagenarian patients who underwent biological vs mechanical valve replacement in this study, a biological valve has more value than a mechanical valve for sexagenarians undergoing aortic valve replacement.
\end{abstract}

Keywords: sexagenarian, Prosthetic valve replacement, Quality of life, Anxiety

\section{Introduction}

Aortic valvular disease is one of the most common acquired heart diseases, and prosthetic valve replacement is the main treatment. The types of prosthetic valves available clinically are divided into prosthetic mechanical and biological valves [1,2]. The advantages of biological valves are that they do not require anticoagulation therapy over the lifetime of the patient after surgery, and patients are not affected by the noise of the valves. However, biological valves

\footnotetext{
*Correspondence: caohua0791@163.com; chenqiang2228@163.com

${ }^{\dagger}$ Li-Wen Wang and Ning Xu contributed equally to this study and share first authorship.

${ }^{1}$ Department of Cardiac Surgery, Fujian Maternity and Child Health Hospital, Affiliated Hospital of Fujian Medical University, Fuzhou, China

Full list of author information is available at the end of the article
}

still have a relatively short service life, and some patients may face the risk of secondary surgery [3]. At present, it is a relatively common opinion that mechanical valves be chosen for young patients while biological valves are chosen for elderly patients in Chinese clinical practice. However, there is no consensus on the type of valve that should be used in patients aged 60-70 $[4,5]$. The choice of artificial valve is related to many factors, such as patient age, sex, education, financial ability, general physical condition, medical compliance, and willingness to accept anticoagulation therapy. This study attempted to use quality of life as a selection factor by comparing and analyzing the quality of life of sexagenarian patients who underwent aortic biological or

(c) The Author(s). 2020 Open Access This article is licensed under a Creative Commons Attribution 4.0 International License, which permits use, sharing, adaptation, distribution and reproduction in any medium or format, as long as you give appropriate credit to the original author(s) and the source, provide a link to the Creative Commons licence, and indicate if changes were made. The images or other third party material in this article are included in the article's Creative Commons licence, unless indicated otherwise in a credit line to the material. If material is not included in the article's Creative Commons licence and your intended use is not permitted by statutory regulation or exceeds the permitted use, you will need to obtain permission directly from the copyright holder. To view a copy of this licence, visit http://creativecommons.org/licenses/by/4.0/ The Creative Commons Public Domain Dedication waiver (http://creativecommons.org/publicdomain/zero/1.0/) applies to the data made available in this article, unless otherwise stated in a credit line to the data. 
mechanical valve replacement, providing a reference for the selection of valve types in this specific age group.

\section{Materials and methods General information}

This study retrospectively analyzed the clinical data of 78 patients admitted to our hospital who underwent aortic prosthetic valve replacement from June 2017 to February 2018. All the patients were divided into two groups according to the prosthetic valve type that the patient chose: the mechanical valve group (40 patients) and the biological valve group (38 patients). Prior to the valve replacement, the patient and his/her family were informed in detail of the special properties of the two kinds of prosthesis valves, their characteristics of use, the need for post-operative anticoagulation therapy, and the durability of the prosthesis valve. After full communication with the doctor, the patient and his/her family selected the corresponding prosthesis valve according to their own situation and their own will. The general information of all patients is shown in Table 1. The inclusion criteria were as follows: patients aged 60 to 70 years old, patients undergoing conventional median thoracotomy, and patients needing conventional aortic biological or mechanical valve replacement. The exclusion criteria were as follows: patients of other age groups, patients undergoing other heart surgery or simultaneous coronary artery bypass grafting, patients

Table 1 Comparison of general data between the two groups

\begin{tabular}{|c|c|c|c|}
\hline & Biological AVR & MechanicalAVR & $P$ values \\
\hline cases & 40 & 38 & \\
\hline age & $55.6 \pm 4.3$ & $54.8 \pm 5.1$ & 0.876 \\
\hline gender & $24 / 16$ & $21 / 17$ & 0.672 \\
\hline \multicolumn{4}{|l|}{ Cardiac function } \\
\hline 1 & 0 & 0 & 0.880 \\
\hline$\|$ & 28 & 26 & \\
\hline III & 12 & 12 & \\
\hline IV & 0 & 0 & \\
\hline \multicolumn{4}{|l|}{ The lesion type } \\
\hline stenosis & 13 & 15 & 0.795 \\
\hline insufficiency & 9 & 7 & \\
\hline stenosis with insufficiency & 18 & 16 & \\
\hline Ejection fraction & $57.9 \pm 11.8$ & $55.3 \pm 13.6$ & 0.682 \\
\hline \multicolumn{4}{|l|}{ The living environment } \\
\hline rural & 29 & 27 & 0.887 \\
\hline city & 11 & 11 & \\
\hline \multicolumn{4}{|l|}{ marriage } \\
\hline married & 37 & 35 & 0.54 \\
\hline unmarried & 1 & 0 & \\
\hline Death of a spouse & 2 & 3 & \\
\hline
\end{tabular}

with cardiac function III-IV, patients with other important organ dysfunction, patients who died of unexplained causes within 1 year after surgery, and patients who were not willing to participate in this study.

\section{Questionnaires}

The Medical Outcomes Study Short Form 36 (SF-36) health scale is characterized by good reliability and validity and is widely used to evaluate the quality of life of all kinds of people [6]. It consists of 36 items, and the eight aspects of health-related quality of life are divided into physical and mental health: 1 . PF: physical functioning; 2. RP: role physical; 3. BP: bodily pain; 4. GH: general health; 5 . VT: vitality; 6. SF: social functioning; 7. RE: role emotional; and 8. MH: mental health $[7,8]$. Each field is explored by different questions, and each question is answered with a different frequency level and a corresponding score. Respondents must choose one of them as the answer, and the final score is calculated based on these answers.

The cardiac anxiety questionnaire (CAQ) is a scale developed by the Department of Psychology of West Virginia University to assess the severity of cardiovascular anxiety symptoms [9]. It consists of 17 items with 3 subscales, including fear (e.g., chest pain and other related sensations), avoidance (e.g., activities believed to cause cardiac symptoms) and attention (awareness of heart-focused sensations such as the heartbeat). Each dimension contains five to eight items, for a total of 17 items. According to the frequency of symptoms, there are 5 levels of responses: 0 for "never", 1 for "rarely", 2 for "sometimes", 3 for "often", and 4 for "always". The higher the score is, the more serious the related psychological disorder [10].

All participants were asked to complete the questionnaire independently, and researchers were allowed to ask questions but were not allowed to interfere with the participants' answers. The SF-36 was completed at discharge and at one-year follow-up, and the CAQ was completed at one-year follow-up.

\section{Statistical analysis}

SPSS 18.0 was used for statistical analysis. According to the anxiety condition after discharge of the two groups of patients in the preliminary survey, we defined $\alpha=$ 0.05 . On the bilateral inspection, the study efficiency was $90 \%$, and the sample sizes of the two groups were calculated as 40 and 38, respectively. The quantitative data are expressed as the mean \pm standard deviation, and the continuous data were tested for normal distribution. An independent sample $t$ test was used for those data conforming to a normal distribution, while the Wilcoxon test was used for those data not conforming to a normal distribution. Quantitative data were compared between groups by the chi-square test. $P<0.05$ was considered statistically significant. 


\section{Results}

As shown in Table 1, there were no significant differences between the two groups in age, sex, cardiac function, living condition or marital status. There was no significant difference in the SF-36 score between the two groups at discharge (Table 2). These results indicated that the two groups of patients were homogeneous and had intergroup comparability.

When comparing the SF-36 scores at one-year followup, the results showed that the scores of physical functioning, role physical, general health, vitality, social functioning, role emotional and mental health in the biological valve group were significantly higher than those in the mechanical valve group, which indicated that the quality of life in the sexagenarians in the biological valve group was higher than that in the mechanical valve group (Table 3). The comparison of CAQ scores at one-year follow-up showed that the fear and anxiety, avoidance and attention scores of the patients in the mechanical valve group were significantly higher than those in the biological valve group, which indicated that the patients in the mechanical valve group showed more anxiety than those in the biological valve group at one year after surgery (Table 4).

\section{Discussion}

Aortic valve disease is one of the most common heart valve diseases and has been on the rise in recent years. Moderate to severe aortic valve disease is often associated with several symptoms, including chest pain, syncope, heart failure, and even sudden death, and requires surgical intervention [11]. At present, the most common surgical method is prosthetic valve replacement, and the types of artificial prosthetic valves commonly used in the clinic can be divided into biological and mechanical valves [12]. The advantages of biological prosthetic valves are that they do not require anticoagulation therapy or monitoring of the coagulation status for the lifetime of the patient, and patients are not affected by the noise of the valve. However, the biological prosthetic valve has the disadvantage of a relatively short service

Table 2 Preoperative comparison of SF-36 scores

\begin{tabular}{llll}
\hline & Biological AVR & Mechanical AVR & P values \\
\hline Physiological function & $63.5 \pm 12.1$ & $64.3 \pm 11.3$ & 0.647 \\
Role physical & $68.3 \pm 11.8$ & $68.4 \pm 15.2$ & 0.728 \\
Bodily pain & $86.2 \pm 13.7$ & $84.6 \pm 10.6$ & 0.682 \\
General health & $60.3 \pm 14.8$ & $61.2 \pm 13.8$ & 0.572 \\
Vitality & $63.1 \pm 17.2$ & $62.5 \pm 14.1$ & 0.389 \\
Social functioning & $65.4 \pm 13.2$ & $67.3 \pm 16.6$ & 0.829 \\
Role emotional & $67.8 \pm 13.6$ & $66.5 \pm 17.8$ & 0.563 \\
Mental health & $61.6 \pm 14.2$ & $60.4 \pm 12.6$ & 0.601 \\
\hline
\end{tabular}

Table 3 Comparison of SF-36 scores one year after surgery

\begin{tabular}{llll}
\hline & Biological AVR & Mechanical AVR & P values \\
\hline Physiological function & $83.4 \pm 15.4$ & $70.3 \pm 11.3$ & 0.035 \\
Role physical & $86.5 \pm 18.7$ & $76.5 \pm 13.6$ & 0.024 \\
Bodily pain & $67.2 \pm 10.4$ & $66.8 \pm 12.4$ & 0.712 \\
General health & $84.2 \pm 15.2$ & $73.6 \pm 15.5$ & 0.032 \\
Vitality & $83.6 \pm 16.7$ & $72.7 \pm 14.2$ & 0.021 \\
Social functioning & $86.5 \pm 15.5$ & $75.2 \pm 17.3$ & 0.040 \\
Role emotional & $88.2 \pm 18.4$ & $76.6 \pm 15.9$ & 0.018 \\
Mental health & $83.7 \pm 16.2$ & $71.6 \pm 14.5$ & 0.029 \\
\hline
\end{tabular}

life, which also limits its application to some extent. Meanwhile, the advantage of mechanical valves is that they can be used for life, but there are also some disadvantages, such as the need for lifelong use of anticoagulants and the obvious noise of the valve [13]. Considering the service life of valves and the relationships between valve type and religion, region, average lifespan of the population, different life values and life expectancy, mechanical prosthetic valves are the first choice for valve replacement in those patients aged under 60 years old in China [2]. The biological prosthetic valve is the first choice for valve replacement in elderly patients aged over 70 years because of life expectancy. For sexagenarian patients with aortic valve lesions, the choice of a mechanical valve means lifelong anticoagulation therapy, while the choice of a biological valve means the possibility of repeat surgery. Choosing the type of prosthetic valve is difficult for Chinese clinicians and patients. Advances in society have led people to care more about quality of life than length of life. In addition to considering the performance of the two prosthetic valves, the postoperative short-term and longterm complications, the survival of patients and the recurrence of the disease, quality of life has also become an important evaluation criterion in choosing the type of prosthetic valve $[14,15]$. This study retrospectively analyzed the quality of life and postoperative anxiety of sexagenarian patients who underwent biological or mechanical aortic valve replacement in our center to provide some reference factors for valve selection for sexagenarian patients to be used in the future.

Through the SF-36 questionnaire survey, we found that the scores of the 7 fields in the biological valve group was significantly higher than those in the mechanical valve group at one-year follow-up, indicating that

Table 4 Comparison of CAQ scores at 1 year after surgery

\begin{tabular}{llll}
\hline & Biological AVR & Mechanical AVR & $P$ values \\
\hline Fear and anxiety & $7.7 \pm 3.6$ & $14.8 \pm 5.5$ & 0.027 \\
Avoidance & $5.2 \pm 2.8$ & $9.1 \pm 3.2$ & 0.039 \\
Attention & $3.3 \pm 2.2$ & $9.6 \pm 4.1$ & 0.018 \\
\hline
\end{tabular}


sexagenarian patients with aortic biological valves experienced better quality of life than those with mechanical valves. Although mechanical valves have longer durability than biological valves, they require anticoagulant therapy for life after surgery. Most patients who undergo prosthetic valve replacement understand the purpose and significance of the anticoagulation therapy as a preventive treatment measure that plays an important role in avoiding valve thrombosis [16-18]. However, the majority of patients are dissatisfied with needing to undergo postoperative anticoagulation therapy. This tedious process requires not only long-term use of anticoagulant drugs but also the detection of blood coagulation function regularly, which makes anticoagulation-related issues (hemorrhage and thrombosis) ominous in the patient's daily life. Patients with mechanical valves need to take anticoagulant drugs every day after surgery and regularly come to the hospital to have blood tests. They are always at risk of anticoagulation-related complications, which greatly affect the quality of life of patients. Another factor that continues to affect the daily life of patients after mechanical aortic valve replacement is valve opening and closing noise [19, 20]. Many studies have also shown the effects of valve noise on patients, which can lead to anxiety, irritability and even sleep disorders. In addition, valve opening and closing sounds from mechanical valves were not only heard by the patients themselves but also by others [21]. This could also explain why not only patients but also their partners have sleep disorders [22].

Patients who have undergone biological aortic valve replacement may be more worried about disease progression due to possible biological valve decay and the need for secondary valve replacement than those who have undergone mechanical aortic valve replacement. In our cardiac anxiety questionnaire, we found the opposite results: patients with mechanical valve replacement showed greater anxiety than those with biological valve replacement. The fear, avoidance and attention scores in the mechanical valve group were significantly higher than those in the biological valve group. Such results were similar to the findings of Aicher, who also believe that aortic valve formation and biological valve replacement have less long-term impact on quality of life than mechanical aortic valve replacement [23]. To analyze the reasons for these results, we determined the main influencing factors: patient concern regarding continuous anticoagulant therapy and continuous valve opening and closing noise following mechanical aortic valve replacement. These factors had a greater impact on quality of life than the possibility of needing a second operation in the biological aortic valve group. In addition, China is a developing country, where the level of primary medical care is suboptimal, and the level of medical care in communities, especially in remote rural areas, is particularly lacking. Most patients with valvular diseases in China come from rural areas, and it is relatively difficult for them to seek medical treatment if there is an anticoagulation problem after the mechanical valve replacement; as such, patients are particularly worried that anticoagulation problems will occur, especially sexagenarian patients. These patients tend to lack medical knowledge, have no adequate medical counseling, and can have no children to help them, and with the memory decline that accompanies aging, the chance that these patients will forget to take their anticoagulants increases correspondingly. These findings may explain why patients in the biological aortic valve group scored higher than the mechanical valve group on the SF-36 and CAQ surveys in this study. Although age, complications, mortality, and specific prosthetic valvular defects may affect sexagenarian patient decisions when choosing between mechanical and biological valves, more consultation should be given to individuals, especially in terms of quality of life and psychological aspects.

There were some limitations in this study. First, this was a retrospective case study and lacked randomization. Second, this was a single-center study with a small sample size, different regions, different cultures, different beliefs might lead to different results [24]. Third, the follow-up time was short, and the quality of life of patients in other age groups and their long-term follow-up data were not studied; in particular, patients in the middle age group received biological valves for fear that the need for reoperation might increase and the quality of life might be affected with mechanical valves. And these might be why Sedrakyan and his team got a different conclusion from ours [24]. There was a statistically significant difference in the age composition of the two groups of patients in their study.

\section{Conclusion}

The quality of life and anxiety scores of sexagenarian patients after aortic valve replacement were better in those wo received a biological valve than those who received a mechanical valve because patients who received a biological valve did not have to worry about the side effects of anticoagulants and the noise related to mechanical valves, even with the potential need for reoperation. Therefore, based on the results of the postoperative quality of life and CAQ surveys, it is more reasonable to choose a biological valve than a mechanical valve for sexagenarian patients undergoing aortic valve replacement.

\section{Abbreviations}

SF-36: The Medical Outcomes Study Short Form 36; CAQ: Cardiac anxiety questionnaire 


\section{Acknowledgements}

We highly acknowledge the contribution by the participating doctors: DaoZhong Chen, Feng Lin, Qi-Min Wang, Han-Fan Qiu, Xue-Shan Huang, DongShan Liao, Xiao-Fu Dai, Zeng-Chun Wang from Department of Cardiovascular Surgery, Union Hospital, Fujian Medical University.

\section{Ethical approval and consent to participate}

The present study was approved by the ethics committee of Fujian Medica University, China and adhered to the tenets of the Declaration of Helsinki.

\section{Authors' contributions}

$\mathrm{QC}$ and $\mathrm{HC}$ designed the study and submitted the manuscript. L-wW, S-tH and NX collected and analyzed data together. L-wW drafted the manuscript. L-wC provided financial support. All authors read the final version of this manuscript and approved for publication.

\section{Funding}

No.

\section{Availability of data and materials}

Data sharing not applicable to this article as no data sets were generated or analyzed during the current study.

\section{Consent for publication}

Not applicable.

\section{Competing interests}

All authors declare that they have no competing interests.

\section{Author details}

'Department of Cardiac Surgery, Fujian Maternity and Child Health Hospital, Affiliated Hospital of Fujian Medical University, Fuzhou, China. ${ }^{2}$ Department of Cardiovascular Surgery, Union Hospital, Fujian Medical University, Fuzhou, China.

Received: 24 January 2020 Accepted: 4 May 2020

Published online: 12 May 2020

\section{References}

1. Unger P, Tribouilloy C. Aortic stenosis with other concomitant Valvular disease: aortic regurgitation, mitral regurgitation, mitral stenosis, or tricuspid regurgitation. Cardiol Clin. 2020;38(1):33-46.

2. Filip G, Litwinowicz R, Kapelak B, Sadowski J, Tobota Z, Maruszewski B, Bartuś K. Trends in isolated aortic valve replacement in middle-aged patients over the last 10 years: epidemiology, risk factors, valve pathology, valve types, and outcomes. Kardiol Pol. 2019;77(7-8):688-95.

3. Sheng W, Zhao G, Chao Y, Sun F, Jiao Z, Liu P, Zhang H, Yao X, Lu F, Zhan $H$, Zhou J, Song T, Tao L, Liu C. Aortic valve replacement with bovine pericardium in patients with aortic valve regurgitation. Int Heart J. 2019; 60(6):1344-9.

4. Maganti K, Rigolin VH, Sarano ME, Bonow RO. Valvular heart disease: diagnosis and management. Mayo Clin Proc. 2010 May:85(5):483-500

5. Piazza N, Bleiziffer S, Brockmann G, Hendrick R, Deutsch MA, Opitz A, Mazzitelli D, Tassani-Prell P, Schreiber C, Lange R. Transcatheter aortic valve implantation for failing surgical aortic bioprosthetic valve: from concept to clinical application and evaluation (part 1). JACC Cardiovasc Interv. 2011;4(7):721-32.

6. McHorney CA, Ware JE Jr, Lu JF, Sherbourne CD. The MOS 36-item shortform health survey (SF-36): III. Tests of data quality, scaling assumptions, and reliability across diverse patient groups. Med Care. 1994:32(1):40-66.

7. Bech-Hanssen O, Caidahl K, Wall B, Mykén P, Larsson S, Wallentin I. Influence of aortic valve replacement, prosthesis type, and size on functional outcome and ventricular mass in patients with aortic stenosis. J Thorac Cardiovasc Surg. 1999;118(1):57-65

8. Piazza N, Bleiziffer S, Brockmann G, Hendrick R, Deutsch MA, Opitz A Mazzitelli D, Tassani-Prell P, Schreiber C, Lange R. Transcatheter aortic valve implantation for failing surgical aortic bioprosthetic valve: from concept to clinical application and evaluation (part 2). JACC Cardiovasc Interv. 2011;4(7): 733-42.

9. Eifert GH, Thompson RN, Zvolensky MJ, Edwards K, Frazer NL, Haddad JW, Davig J. The cardiac anxiety questionnaire: development and preliminary validity. Behav Res Ther. 2000;38(10):1039-53.
10. Last AN, English J, Pote H, Shafran R, Owen T, Kaski JP. Anxiety in children attending a specialist inherited cardiac arrhythmia clinic: a questionnaire study. BMJ Paediatr Open. 2018 Aug 30;2(1):000271.

11. Akmaz B, Zipfel N, Bal RA, Rensing BJWM, Daeter EJ, van der Nat PB. Developing process measures in value-based healthcare: the case of aortic valve disease. BMJ Open Qual. 2019;8(4):000716.

12. Kytö V, Sipilä J, Ahtela E, Rautava P, Gunn J. Mechanical versus biological prostheses for surgical aortic valve replacement in patients aged 50-70. Ann Thorac Surg. 2019;28:S0003-4975(19) 31765-5.

13. Zhu Z, Li Y, Meng X, Han J, Li Y, Liu K, Shen J, Qin Y, Zhang H. New warfarin anticoagulation management model after heart valve surgery: rationale and design of a prospective, multicentre, randomised trial to compare an internet-based warfarin anticoagulation management model with the traditional warfarin management model. BMJ Open. 2019;9(12):032949.

14. Lunardi VL. Problems with the concept of health regarding patients' beliefs. Rev Gaucha Enferm. 1999;20(1):26-40.

15. Maclsaac S, Jaffer $I H$, Belley-Côté EP, McClure GR, Eikelboom JW, Whitlock RP. How did we get Here?: a historical review and critical analysis of anticoagulation therapy Following mechanical valve replacement. Circulation. 2019:140(23):1933-42.

16. Mazer CD, Bhatt DL, Verma S. Anticoagulation Following TAVR: No clear answer yet. J Am Coll Cardiol. 2019:73(1):22-8.

17. Dannenberg L, Zako S, Mourikis P, Veulemans V, Kelm M, Zeus T, Polzin A. Oral anticoagulation therapy and progression of calcific aortic valve stenosis: factor Xa versus factor lla inhibition? Pharmacology. 2019;104(3-4):212-4.

18. Khetarpal V, Mahajan N, Madhavan R, Batra S, Mopala P, Sagar A, Rapolu P, Nangia S, Afonso L. Calcific aortic valve and spontaneous embolic stroke: a review of literature. J Neurol Sci. 2009;287(1-2):32-5.

19. Koertke H, Hoffmann-Koch A, Boethig D, Minami K, Breymann T, El-Arousy $M$, Seifert D, Koerfer R. Does the noise of mechanical heart valve prostheses affect quality of life as measured by the SF-36 questionnaire? Eur J Cardiothorac Surg. 2003;24(1):52-7.

20. Blome-Eberwein SA, Mrowinski D, Hofmeister J, Hetzer R. Impact of mechanical heart valve prosthesis sound on patients' quality of life. Ann Thorac Surg. 1996:61(2):594-602.

21. Hoppensteadt D, Fareed J, Klein AL, Jasper SE, Apperson-Hansen C, Lieber EA, Katz WE, Malouf JF, Stoddard MF, Pape LA. Comparison of anticoagulant and anti-inflammatory responses using enoxaparin versus unfractionated heparin for transesophageal echocardiography-guided cardioversion of atrial fibrillation. Am J Cardiol. 2008;102(7):842-6.

22. Limb D, Kay PH, Murday AJ. Problems associated with mechanical heart valve sounds. Eur J Cardiothorac Surg. 1992:6(11):618-20.

23. Aicher D, Holz A, Feldner S, Köllner V, Schäfers HJ. Quality of life after aortic valve surgery: replacement versus reconstruction. J Thorac Cardiovasc Surg. 2011;142(2):19-24

24. Sedrakyan A, Hebert P, Vaccarino V, Paltiel AD, Elefteriades JA, Mattera J, Lin Z, Roumanis SA, Krumholz HM. Quality of life after aortic valve replacement with tissue and mechanical implants. J Thorac Cardiovasc Surg. 2004;128(2): 266-72.

\section{Publisher's Note}

Springer Nature remains neutral with regard to jurisdictional claims in published maps and institutional affiliations.

Ready to submit your research? Choose BMC and benefit from

- fast, convenient online submission

- thorough peer review by experienced researchers in your field

- rapid publication on acceptance

- support for research data, including large and complex data types

- gold Open Access which fosters wider collaboration and increased citations

- maximum visibility for your research: over $100 \mathrm{M}$ website views per year

At BMC, research is always in progress.

Learn more biomedcentral.com/submissions 